\title{
NSE \& S100B protein blood level assessment during a long-distance trail race
}

\author{
Évaluation du taux plasmatique de la NSE et de la S100B \\ au cours d'une épreuve de course à pieds d'ultra endurance
}

\author{
Romain Jouffroy ${ }^{1,2,3}$ \\ Barbara Alves ${ }^{1}$ \\ Benoit Mauvieux ${ }^{4,5}$ \\ Luc Mallet $6,7,8$ \\ Jean-Louis Beaudeux ${ }^{9,10}$ \\ Charles-Henry Cottart ${ }^{9,10}$ \\ ${ }^{1}$ Intensive care unit, Anaesthesiology, \\ SAMU, Necker-Enfants malades \\ Hospital, Assistance Publique - \\ Hôpitaux de Paris, Paris, France \\ 2 Departments of anaesthesia, \\ Clinical epidemiology and biostatistics, \\ Michael De Groote school of medicine, \\ Faculty of health sciences, McMaster \\ University, Hamilton, Ontario, Canada \\ ${ }^{3}$ IRMES - Institute for research in \\ medicine and epidemiology of sport, \\ Paris, France \\ ${ }^{4}$ UMR-S 1075-COMETE Mobilités \\ vieillissement, pathologie, santé, \\ Pôle des formations et de recherche \\ en santé (PFRS), Université de Caen \\ Normandie, Inserm, Caen, France \\ ${ }^{5}$ Unité de chronobiologie, \\ Fondation Rothschild, Paris, France \\ ${ }^{6}$ Assistance Publique-Hôpitaux \\ de Paris, Psychiatry department, \\ Hôpitaux universitaires Henri Mondor - \\ Albert Chenevier, Université Paris-Est, \\ Créteil, France \\ 7 Sorbonne Universités, \\ UPMC Université Paris 06, CNRS, \\ Inserm, Institut du cerveau et de la \\ moelle épinière (ICM), Paris, France \\ ${ }^{8}$ Department of mental health and \\ psychiatry, Global health institute, \\ University of Geneva, Geneva, \\ Switzerland
}

Article received June 9, 2019, accepted September 07, 2019

\begin{abstract}
The acute and chronic consequences of long-distance running on brain function have received little attention. The impact of such a hard-physical burden associated with sleep privation during such events such has never been explored in terms of neuropsychological function and brain damage. Methods. Blood samples were collected from 4 athletes before, during and at the end of one of two races: Grand Raid de la Réunion 2017 (GRR: $165 \mathrm{~km}$, elevation gain: 9529 m, 2 runners) and Trail de la Bourbon 2017 (TB: $111 \mathrm{~km}$, elevation gain: $6433 \mathrm{~m}, 2$ runners). Serum S100B and NSE levels were measured for each runner before, during and after the race. Results. Serum S100B levels (normal range: $<0.15 \mu \mathrm{g} / \mathrm{L}$ ) increased early during the race and remained high up to the end of the race in all 4 runners (range: $0.17-0.59 \mu \mathrm{g} / \mathrm{L}$ ). NSE level (normal range: $<15 \mu \mathrm{g} / \mathrm{L}$ ) increased in 3 of the 4 runners (range: 16.8-39.2 $\mu \mathrm{g} / \mathrm{L}$ ). Conclusions. This preliminary study shows the potential interest of S100B and NSE serum assessment during long-distance races. Further studies are needed to confirm these results and to investigate the origins and significance of this increase in brain injury markers.
\end{abstract}

Key words: running, en durance exercise, S100B, NSE, brain damage

Résumé. Les conséquences à court et long terme de la course à pieds d'ultra endurance sur la fonction cérébrale sont peu connues. L'impact neuropsychologique et fonctionnel cérébral de telles épreuves nécessitant la privation de sommeil n'a jamais été exploré. Méthodes. En 2107, des prélèvements sanguins ont été effectués afin de mesurer les taux plasmatiques de S100B et de NSE chez 4 coureurs avant, pendant et à la fin de leur participation au Grand Raid de La Réunion (GRR : 165 kilomètres avec 9529 mètres de dénivelé positif, 2 coureurs) ou au Trail de la Bourbon (TB : 111 kilomètres avec 6433 mètres de dénivelé positif, 2 coureurs). Résultats. Le taux plasmatique de S100B (valeur normale $<0,15 \mu \mathrm{g} / \mathrm{L}$ ) augmente au cours de l'épreuve et reste élevé à la fin de la course chez les 4 coureurs $(0,17-0,59 \mu \mathrm{g} / \mathrm{L})$ alors que celui de la NSE (valeur normale $<0,15 \mu \mathrm{g} / \mathrm{L}$ ) augmente uniquement chez 3 coureurs $(16,8-39,2 \mu \mathrm{g} / \mathrm{L})$. Conclusion. Cette étude préliminaire met en évidence la faisabilité de la mesure des taux plasmatiques de NSE et S100B au cours d'une épreuve de course à pieds d'ultra endurance. Des études complémentaires sont nécessaires pour confirmer ces résultats préliminaires, préciser les origines ainsi que la signification de cette élévation de marqueurs de souffrance cérébrale.

Mots clés : course à pieds, endurance, S100B, NSE, souffrance cérébrale 
${ }^{9}$ Department of clinical chemistry,

Necker-Enfants malades Hospital,

Assistance Publique - Hôpitaux

de Paris, Paris, France

10 Université de Paris,

Faculté de pharmacie, Paris, France

Long-distance races, "ultra-trails", are gaining in popularity and have become widespread all over the world [1]. While beneficial effects of regular physical exercise are well known [2], the physiological and/or pathological consequences of long-distance races $(>100 \mathrm{~km}$ ) have been poorly studied. Moreover, most of these long races require at least one night without any sleep. To our knowledge, the impact of such a hard-physical burden associated with sleep deprivation during ultra-trail races has never been explored in terms of neuropsychological function (attention, concentration and vigilance) and brain damage. While the effects of sleep deprivation and prolonged physical activity on vigilance and attention are well known [3], the biological impact of such situations on the brain has not yet been studied. The location of this type of race (mountains, wild) makes it difficult to directly evaluate brain function using conventional approaches (neuropsychological tests) and, moreover, runners do not have enough time during a race to devote to conventional tests. Given these constraints, neurological biomarkers appear to be a potential means of assessing brain function. Among these markers, protein S100B (S100B) and neuron-specific enolase (NSE) have been used as biomarkers of brain damage in various traumatic and nontraumatic neurological disorders both in adults and children [4-7]. S100B and NSE release may also result from brain blood circulation changes [8, 9]. Increases in S100B have been reported after various types of exercise [10-14] while the relation between NSE variations and exercise are less clear [15]. Most of these observations were established in "before and after" designed studies. It has been shown that these biomarkers increased at the end of exercise, but this kind of design did not allow investigators to determine whether the increases occurred early or late $[8,9]$.

To our knowledge, NSE and S100B levels had never been studied during long-distance race challenges. This preliminary study aimed to investigate the interest of measuring serum levels of NSE and S100B during an acute longdistance trail race as biomarkers of brain impairment and/or adaptation.

\section{Methods}

\section{Participants}

Six Caucasian subjects were initially involved in this prospective observational study; two subjects withdrew from the study due to injury and no serum samples except for the one taken before the race were available for them. These two subjects were excluded from the analysis.

Of the four remaining subjects (all physicians), two participated in the $164 \mathrm{~km}$ Grand Raid de La Réunion 2017 (GRR), with a total ascent of 9,917 m, and two participated in the Trail de la Bourbon 2017 (TB) $(111 \mathrm{~km}$, total ascent $6,433 \mathrm{~m}$ ). During the two races, all participants were free to take in food and water when required. The race organizing committee approved the study protocol.

All participants gave their written informed consent for participation before the start of the race. As the participants were the researchers, no ethical committee approval was required.

\section{Sample processing}

Venous blood samples $(2 \mathrm{~mL})$ were collected by a nurse before the race (start), during the race at intermediate checkpoints $(73 \mathrm{~km}$ for the TB, and $65 \mathrm{~km}$ and $127 \mathrm{~km}$ for the GRR) and at the end of the race (111 km for the TB and 165 $\mathrm{km}$ for the GRR). Blood withdrawal involved a 2 min-stop at each intermediate checkpoint.

Blood samples were immediately centrifuged and the serum was frozen on dry ice. Frozen samples were sent to the Clinical chemistry lab of Necker-Enfants malades hospital and stored at $-80^{\circ} \mathrm{C}$. Serum S100B and NSE levels were measured immediately using a DiaSorin Liaison XL analyser and DiaSorin reagents according to the manufacturer's instructions. No marked hemolysis was pointed out in any sample. Hematocrit level were measured immediately using Stat Profile Prime - Nova Biomedical ${ }^{\circledR}$.

\section{Results}

\section{Parameters and performance}

The characteristics of the study participants and their performance during the race are summarized in table 1.

S100B and NSE kinetics, blood glucose level and hematocrit are summarized in table 2. For all runners, S100B levels was below the threshold value $(<0.15 \mu \mathrm{g} / \mathrm{L})$ at the start of the race and increased above this value at the intermediate checkpoints and at the end of the race. In contrast, serum levels of NSE remained normal throughout the race for runner 1. Surprisingly, runner 2 began with an 
Table 1. Characteristics of the study participants and performances during the race.

\begin{tabular}{|c|c|c|c|c|c|c|}
\hline & \multicolumn{2}{|c|}{ Runner 1} & Runner 2 & \multicolumn{2}{|c|}{ Runner 3} & Runner 4 \\
\hline Age (years) & \multicolumn{2}{|c|}{43} & 39 & \multicolumn{2}{|c|}{37} & 35 \\
\hline Body weight $(\mathrm{kg})$ & \multicolumn{2}{|c|}{80} & 77 & \multicolumn{2}{|c|}{72} & 56 \\
\hline Height $(\mathrm{cm})$ & \multicolumn{2}{|c|}{180} & 178 & \multicolumn{2}{|c|}{172} & 165 \\
\hline & $\begin{array}{l}\text { GRR } \\
\text { Distance }\end{array}$ & $\begin{array}{l}\text { Runner } 1 \\
\text { Lap time }\end{array}$ & $\begin{array}{l}\text { Runner } 2 \\
\text { Lap time }\end{array}$ & $\begin{array}{l}\text { TB } \\
\text { Distance }\end{array}$ & $\begin{array}{l}\text { Runner } 3 \\
\text { Lap time }\end{array}$ & $\begin{array}{l}\text { Runner } 4 \\
\text { Lap time }\end{array}$ \\
\hline First stop & $65 \mathrm{~km}$ & $15.5 \mathrm{~h}$ & $15.7 \mathrm{~h}$ & $73 \mathrm{~km}$ & $15.5 \mathrm{~h}$ & $18.5 \mathrm{~h}$ \\
\hline Second stop & $127 \mathrm{~km}$ & $39.7 \mathrm{~h}$ & $36.7 \mathrm{~h}$ & Not applice & & \\
\hline End & 165 km & $57.9 \mathrm{~h}$ & $50.9 \mathrm{~h}$ & $111 \mathrm{~km}$ & $27.9 \mathrm{~h}$ & $39.2 \mathrm{~h}$ \\
\hline
\end{tabular}

GRR: Grand Raid de la Réunion 2017; TB: Trail de la Bourbon 2017.

Table 2. Individual serum values of S100B ( $\mu \mathrm{g} / \mathrm{L})$, NSE ( $\mu \mathrm{g} / \mathrm{L})$ and hematocrit $(\%)$.

\begin{tabular}{|c|c|c|c|c|c|}
\hline GRR & Runner 1 & Runner 2 & TB & Runner 3 & Runner 4 \\
\hline \multicolumn{6}{|c|}{ S100B concentration } \\
\hline Start & 0.06 & 0.14 & Start & 0.04 & 0.05 \\
\hline First stop & 0.27 & 0.22 & First stop & 0.38 & 0.55 \\
\hline Second stop & 0.29 & IBS & End & 0.56 & 0.59 \\
\hline End & 0.28 & 0.17 & & & \\
\hline \multicolumn{6}{|c|}{ NSE concentration } \\
\hline Start & 11.3 & 19.1 & Start & 11.9 & 12.8 \\
\hline First stop & 7.2 & 25.7 & First stop & 26.1 & 14.9 \\
\hline Second stop & 11.9 & 20.0 & End & 39.2 & 16.8 \\
\hline End & 13.4 & 13.0 & & & \\
\hline \multicolumn{6}{|l|}{ Hematocrit } \\
\hline Start & 42 & 45 & Start & 47 & 45 \\
\hline First stop & 47 & 49 & First stop & 43 & 36 \\
\hline Second stop & 41 & 40 & End & 43 & 34 \\
\hline End & 43 & 43 & & & \\
\hline
\end{tabular}

GRR: Grand Raid de la Réunion 2017; TB: Trail de la Bourbon 2017; IBS: insufficient blood sample. Results in bold are above the normal threshold $(>0.15 \mu \mathrm{g} / \mathrm{L}(\mathrm{S} 100 \mathrm{~B})$ and $>15 \mu \mathrm{g} / \mathrm{L}(\mathrm{NSE}))$.

abnormal level of NSE that remained high during the race but was below the threshold value of $<15 \mu \mathrm{g} / \mathrm{L}$ at the end of the race. The initial level at $19.1 \mu \mathrm{g} / \mathrm{L}$ of runner 2 could be explained at least in part by sleep deprivation in the plane the night before the start of the race [16]. Hematocrit is reported as marker of the runner's hydratation state.

\section{Discussion}

In this preliminary study, we observed an early and marked increase in serum S100B levels in all four runners taking part in a long-distance running race. In contrast, NSE levels were above normal in only three of the four runners. To our knowledge, this study provides the first "per effort" values of serum S100B and NSE levels during an ultra-trail race. Extreme exercise may induce neurological disorders by various mechanisms including: race duration (with at least one night without sleeping) [13], repetition of brain trauma secondary to intensive and prolonged running [10], modification of brain blood circulation [17], alteration of systemic inflammation [13] and oxygen delivery [18]. The difference between S100B and NSE concentration profiles during the race could be explained by the fact that these two markers are known to reflect different types of cerebral impairment. As $\mathrm{S} 100 \mathrm{~B}$ concentration in cerebrospinal fluid is 10-times greater than in blood, an increase in serum concentrations of S100B is considered to be a result of blood-brain barrier alterations $[15,19]$ and could depend on exercise intensity [10]. However, the early increase in S100B serum levels observed in our study may have resulted from multiple origins including sleep deprivation [20] and/or from cerebral trauma [21] and/or digestive tract inflammation [22]. On the other hand, NSE is considered to be a marker of neuron damage, neuron destruction, ischemic damage and structural impairment of neuronal cells $[10,13,18]$, rather than 
blood barrier alterations. However, NSE is also involved in the regulation of inflammation following any neuronal injury [23] and increases in NSE serum levels may also result from haemolysis related to exercise [6] and/or muscle damage [3].

In our study, while both brain damage biomarkers were increased, we were not able to determine whether the increases in S100B and NSE were the result of specific cerebral damage rather than non-cerebral damage.

This study has several limitations. First, the sample size was very small and included only male subjects. Second, there was no control group in the study design. Third, contrary to NSE, S100B is not selective to cerebral injury; thus, herein results may be affected by muscular damages related to prolonged exercise. Finally, it was not possible to determine the correlation between biomarker levels and performance due to the lack of power related to the small sample size. Further studies are therefore required to confirm these results and to identify the mechanism of origin of the increase in S100B and NSE serum levels.

\section{Conclusion}

Our preliminary study shows the interest of investigating S100B and NSE serum concentrations during long-distance races. These biomarkers could allow a better understanding of the potential impact of extreme races on body physiology. However, due to the small sample size, these results must be confirmed in a larger population of runners. Further studies should integrate designs to evaluate the impact of sleep deprivation on S100B and NSE levels and whether the increase in brain biomarkers is due specifically to brain injury or to non-specific damage due to other organ injury.

Conflict of interest: none of the authors has any conflict of interest to disclose.

Acknowledgements. We thank the Grand Raid de la Réunion race organizers, the Human Adaptability Project and the Fondamental Suisse Foundation for their material support, Xavier Combes, MD, $\mathrm{PhD}$ - deputy chair of SAMU 974 La Réunion, France, Patrice Combe, MD, Head of biochemistry Saint-Denis La Réunion hospital, La Réunion, France and Olivier Hermine, MD, PhD, Deputy chair of Haematology, Necker-Enfants malades hospital, Paris, France. We also thank Arnaud Risbourg, Emmanuel Techer, Margot Morgiève and Bruno Lemarchand for their participation in the study, and Anne Weismann and Clémentine Caspar for their help in blood sampling during the race. We thank Dr Boualem Hammadi for his technical support.

\section{References}

1. Shiroma EJ, Lee IM. Physical activity and cardiovascular health: lessons learned from epidemiological studies across age, gender, and race/ethnicity. Circulation 2010;122:743-52.

2. Cejka N, Rust CA, Lepers R, Onywera V, Rosemann T, Knechtle B. Participation and performance trends in 100-km ultra-marathons worldwide. J Sports Sci $2014 ; 32: 354-66$.

3. Chosa E, Sekimoto T, Sonoda N, Yamamoto K, Matsuda H, Takahama $\mathrm{K}$, et al. Evaluation of human beta-enolase as a serum marker for exerciseinduced muscle damage. Clin J Sport Med $2003 ; 13: 209-12$.

4. Du W, Li H, Sun J, Xia Y, Zhu R, Zhang X, et al. The prognostic value of serum neuron specific enolase (NSE) and S100B level in patients of acute spinal cord injury. Med Sci Monit $2018 ; 24$ : 4510-5.

5. Meshcheryakov SV, Semenova ZB, Lukianov VI, Sorokina EG, Karaseva OV. Prognosis of severe traumatic brain injury outcomes in children. Acta Neurochir Suppl 2018; 126:11-6.

6. Planche V, Brochet C, Bakkouch A, Bernard M. Importance of hemolysis on neuron-specific enolase measurement. Ann Biol Clin (Paris) $2010 ; 68: 239-42$.

7. Yardan T, Erenler AK, Baydin A, Aydin K, Cokluk C. Usefulness of S100B protein in neurological disorders. J Pak Med Assoc 2011;61: 276-81.

8. Goettel N, Burkhart CS, Rossi A, Cabella BC, Berres M, Monsch AU, et al. Associations between impaired cerebral blood flow autoregulation, cerebral oxygenation, and biomarkers of brain injury and postoperative cognitive dysfunction in elderly patients after major noncardiac surgery. Anesth Analg 2017 ; 124 : 934-42.

9. Shinozaki K, Oda S, Sadahiro T, Nakamura M, Abe R, Nakada TA, et al. Serum S-100B is superior to neuron-specific enolase as an early prognostic biomarker for neurological outcome following cardiopulmonary resuscitation. Resuscitation $2009 ; 80: 870-5$.

10. Koh SX, Lee JK. S100B as a marker for brain damage and blood-brain barrier disruption following exercise. Sports Med 2014; 44 :369-85.

11. Mokhtarzade M, Motl R, Negaresh R, Zimmer P, Khodadoost M, Baker JS, et al. Exercise-induced changes in neurotrophic factors and markers of blood-brain barrier permeability are moderated by weight status in multiple sclerosis. Neuropeptides 2018; $70: 93-100$.

12. Rogatzki MJ, Keuler SA, Harris AE, Ringgenberg SW, Breckenridge RE, White JL, et al. Response of protein S100B to playing American football, lifting weights, and treadmill running. Scand J Med Sci Sports $2018 ; 28: 2505-14$.

13. Roh HT, Cho SY, Yoon HG, So WY. Effect of exercise intensity on neurotrophic factors and blood-brain barrier permeability induced by oxidative-nitrosative stress in male college students. Int J Sport Nutr Exerc Metab 2017; $27: 239-46$.

14. Schulte S, Podlog LW, Hamson-Utley JJ, Strathmann FG, Struder HK. A systematic review of the biomarker S100B: implications for sportrelated concussion management. J Athl Train 2014 ; 49 : 830-50.

15. Laribi S, Kansao J, Borderie D, Collet C, Deschamps P, Ababsa R, et al. S100B blood level measurement to exclude cerebral lesions after minor head injury: the multicenter STIC-S100 French study. Clin Chem Lab Med 2014; 52: 527-36.

16. Benedict C, Cedernaes J, Giedraitis V, Nilsson EK, Hogenkamp PS, Vågesjö E, et al. Acute sleep deprivation increases serum levels of 
neuron-specific enolase (NSE) and S100 calcium binding protein B (S-100B) in healthy young men. Sleep 2014 ; 37: 195-8.

17. Aydin I, Algin A, Poyraz MK, Yumrutas O. Diagnostic value of serum glial fibrillary acidic protein and S100B serum levels in emergency medicine patients with traumatic versus nontraumatic intracerebral hemorrhage. Niger J Clin Pract 2018; 21 : 1645-50.

18. Lefferts WK, Babcock MC, Tiss MJ, Ives SJ, White CN, Brutsaert TD, et al. Effect of hypoxia on cerebrovascular and cognitive function during moderate intensity exercise. Physiol Behav 2016; 165: 108-18.

19. Zongo D, Ribereau-Gayon R, Masson F, Laborey M, Contrand B, Salmi LR, et al. S100-B protein as a screening tool for the early assessment of minor head injury. Ann Emerg Med 2012; 59:209-18.

20. Zhang P, Tan CW, Chen GH, Ge YJ, Xu J, Xia L, et al. Patients with chronic insomnia disorder have increased serum levels of neurofilaments, neuron-specific enolase and S100B: does organic brain damage exist? Sleep Med $2018 ; 48$ : 163-71.

21. Papa L, Mittal MK, Ramirez J, Ramia M, Kirby S, Silvestri S, et al. In children and youth with mild and moderate traumatic brain injury, glial fibrillary acidic protein out-performs S100beta in detecting traumatic intracranial lesions on computed tomography. J Neurotrauma $2016 ; 33: 58-64$.

22. Leach ST, Yang Z, Messina I, Song C, Geczy CL, Cunningham AM, et al. Serum and mucosal S100 proteins, calprotectin (S100A8/S100A9) and S100A12, are elevated at diagnosis in children with inflammatory bowel disease. Scand J Gastroenterol 2007;42: 1321-31.

23. Haque A, Polcyn R, Matzelle D, Banik NL. New insights into the role of neuron-specific enolase in neuro-inflammation, neurodegeneration, and neuroprotection. Brain Sci $2018 ; 8$ : E33. 